\title{
PERIODISMO PROFESIONAL: CONFIGURACIÓN DEL CAMPO, AGREMIACIÓN Y ESFERA PÚBLICA EN EL ECUADOR, 1940-1950
}

\section{PROFESSIONAL JOURNALISM: FIELD CONFIGURATION, UNIONIZATION AND PUBLIC SPHERE IN ECUADOR, 1940-1950}

\section{LEÓN ESPINOSA O. ${ }^{1}$ CAROLINA LARCO C. ${ }^{2}$}

Recibido: 30 de enero de 2017 Aceptado: 6 de marzo de 2017

\footnotetext{
${ }^{1}$ Pontificia Universidad Católica del Ecuador, Facultad de Comunicación, Lingüística y Literatura, Escuela de Comunicación, Quito, Ecuador, (lespinosao @puce.edu.ec).

${ }^{2}$ Pontificia Universidad Católica del Ecuador, Facultad de Comunicación, Lingüística y Literatura Escuela de Comunicación, Quito, Ecuador, (eclarco @puce.edu.ec).
} 



\title{
PERIODISMO PROFESIONAL: CONFIGURACIÓN DEL CAMPO, AGREMIACIÓN Y ESFERA PÚBLICA EN EL ECUADOR, 1940-1950
}

\author{
PROFESSIONAL JOURNALISM: FIELD \\ CONFIGURATION, UNIONIZATION AND PUBLIC \\ SPHERE IN ECUADOR, 1940-1950
}

León Espinosa O., Carolina Larco C.

PALABRAS CLAVE: historia, periodismo, campo profesional, capital simbólico, esfera pública.

KEY WORDS: history, journalism, professional field, symbolic capital, public sphere.

\section{RESUMEN}

Este artículo explora el origen del campo profesional del periodismo, ubicado entre 1940 y 1950, con el rol protagónico de la Unión Nacional de Periodistas (UNP) a través de la campaña de alfabetización y la difusión de la cultura nacional. Este proceso se interpreta por medio del uso del concepto de "campo" de Pierre Bourdieu, que permite reconocer el espacio social de un grupo, su capital simbólico, la identidad e intereses de gremio. La UNP albergó los intereses laborales de los periodistas, impulsó su posicionamiento social y el intento de transición de un periodismo empírico a uno profesional. Identificó un capital simbólico: el dominio de la escritura cuyo uso les permitiría intervenir en la esfera pública. Sin embargo, este giro hacia el periodismo profesional no implicó 
una ruptura total con el pasado, por rezagos de tradiciones inscritas en el imaginario social. Los periodistas asumieron funciones del ámbito público, como la alfabetización y el reconocimiento de la ciudadanía, descuidadas por el estado, circunstancias que restringieron la ansiada autonomía del campo profesional respecto al poder político.

\section{ABSTRACT}

This article explores the origin of the professional field of journalism, located between 1940 and 1950, with the leading role of the Unión Nacional de Periodistas (UNP) through the literacy campaign and the diffusion of the national culture. This process is interpreted through the use of the concept "field" of Pierre Bourdieu, which allows to recognize the social space of a group, its symbolic capital, the identity and interests of guild. The UNP housed the labor interests of the journalists, impulse its social positioning and the attempt to transition from empirical to professional journalism. Identified a symbolic capital: the domain of writing whose use allow them to intervene in the public sphere. However, this turn to professional journalism did not imply a total rupture with the past, due to the lags of traditions inscribed in the social imaginary. The journalists assumed functions of public domain, as the literacy and the acknowledgment of the citizenship, neglected by the state, circumstances that restricted the desired autonomy of the professional field about the political power.

\section{INTRODUCCIÓN}

Los estudios sobre historia de la comunicación y del periodismo en el Ecuador son aún escasos o, al menos, se encuentran dispersos en distintas épocas, desde fines del siglo XVIII hasta inicios del siglo XX. Algunos trabajos contemporáneos exponen, con una perspectiva panorámica y evolucionista, a grandes trazos, el desarrollo de los medios de comunicación desde la prensa escrita hasta la llegada de la radio y de la televisión.' En cambio, los estudios

${ }^{1}$ Hallo, W. (1992). "Síntesis histórica de la comunicación y el periodismo en el Ecuador (1992). En esta obra se recoge información de los primeros periódicos desde fines del siglo XVIII hasta el siglo XIX, con una mira- 
realizados en épocas anteriores presentan, con detalle, el origen de la prensa y de las primeras publicaciones; muestran datos sobre los redactores e impresores en las ciudades principales, por lo que constituyen fuentes valiosas para explorar la historia de la comunicación y del periodismo; aunque consisten en estudios de carácter descriptivo que podrían ser re-significados con nuevos enfoques historiográficos.

Varios autores han puesto atención en los personajes insignes, a manera de iconos del periodismo de todos los tiempos. Sin embargo, el estado del arte de la historiografía del periodismo y de la comunicación en el Ecuador deja al descubierto la necesidad de abordar, con mayor especificidad, épocas recientes, pues se ha investigado muy poco acerca de este campo desde mediados del si- glo XX hasta la actualidad. Estos grandes vacíos deberían ser cubiertos con enfoques renovados, más allá de la perspectiva positivista, anclada en el desarrollo de los medios de comunicación, y de las narraciones centradas únicamente en los personajes, a favor de enfoques integrales, desde la historia social y cultural, con la cual se podría reconocer la agencia de los actores sociales, grupos o colectivos, en contextos específicos. Esta forma de aproximarse al pasado planteará interrogantes de valor contemporáneo sobre el ejercicio periodístico, su rol en la sociedad, en la cultura, en la política, en el cambio o la continuidad de sus prácticas, sus alcances y límites.

El propósito de este artículo es abrir nuevos caminos de investigación sobre la historia del periodismo en el Ecuador a través del rastreo del origen

da panorámica y con un relato descriptivo de los principales periódicos y redactores. De igual manera, el texto del autor José Villamarín es un estudio descriptivo acerca de las eras de la comunicación en el mundo; incluye información de ciertos hitos en el Ecuador del siglo XX. Se trata de un texto con información importante, varios datos acerca del periodismo, pero al ser una síntesis, escrita de manera didáctica, se limita el espacio para la reflexión.

2 Entre los principales textos se encuentra la obra de Camilo Destruge intitulada: Historia de la Prensa de Guayaquil (1982), que presenta información relevante desde la época de Independencia hasta 1920, centrada en dicha ciudad con abundantes datos acerca de los periódicos fundados. Aquí el autor establece una relación entre el contenido de los periódicos con el contexto político en el cual emergían. Su contenido se refiere exclusivamente a la prensa escrita dada la época de estudio en la que no existía aún la radio ni la televisión. Con respecto a la prensa escrita vale la pena mencionar las obras de Alexander Stols, entre las cuales citamos "La historia de la imprenta en el Ecuador" en la que se aprecia un recorrido desde la llegada de las primeras imprentas a este territorio desde fines de la época colonial hasta los primeros años de la República. Esta obra recoge importantes fuentes primarias, pero al igual que la obra de Destruge llega hasta la prensa del siglo XIX, sin el abordaje del desarrollo del periodismo como campo. El texto: "Periodismo y Medios de Comunicación Social" (2004) de la autora Alexandra Ayala, registra con una visión panorámica los principales hitos de la historia de la comunicación del Ecuador, incluyendo la visión sobre la prensa, la radio y la televisión. 
del campo profesional, ubicado entre 1940 y 1950, desde la creación de la Unión Nacional de Periodistas (UNP), en el contexto del crecimiento de las ciudades y de los procesos de modernización de la época. La UNP definió los intereses de los periodistas "de oficio", forjados en las salas de redacción de los periódicos, en pro de la defensa de sus derechos laborales, como todo gremio; e impulsó el ejercicio profesional moderno que, en teoría, debía responder a las necesidades de la sociedad ecuatoriana y a la resolución de los acuciantes problemas de mediados del siglo XX. De esta manera, la fundación de la UNP constituyó un hito y, a la vez, un punto de partida de la configuración del campo profesional, con alcances significativos en la esfera pública, pero con límites en la autonomía del campo respecto a la dimensión política e ideológica. El presente artículo enfoca el quehacer de la UNP, en cuanto a algunas actividades primordiales, educativas y culturales, realizadas en la esfera pública, las mismas que reflejan para aquella época una relación visible entre los empresarios de los medios, los periodistas agremiados y el estado, que confió una función primordial al periodismo, tal como la educación por medio de la campaña de alfabetización iniciada en la década de los 40. La UNP, por su parte, asumió la difusión de la cultura nacional hegemónica, como una estrategia inteligente y persuasiva, orientada a su posicionamiento social.

Esta idea de la poca autonomía del campo periodístico, propuesta a manera de hipótesis en este artículo, se inspira en un sugerente estudio titulado: Los espacios perturbadores del humor. Revistas, arte y caricatura 1918-1930 (Bedoya, 2007), en el cual se plantea que, a diferencia de los caricaturistas, quienes en la primera mitad del siglo XX habían logrado configurar espacios de movilidad y de transgresión, gracias al humor gráfico, en las revistas ilustradas y circuitos artísticos, el estilo periodístico de la prensa se encontraba "intimamente vinculado al acontecer coyuntural, social o político del país". Por contraste al campo artístico ${ }^{3}$, el incipiente campo del periodismo profesional parecía aún estar asociado a un rol tradicional de actor político, proveniente del pasado.

Por otra parte, Hernán Ibarra (2015) propone para mediados del siglo XX ideas relevantes a seguir en este artículo. Plantea la relación entre el estado y los medios impresos, sea por la publicidad, por las relaciones con las figuras

${ }^{3}$ Según Bedoya, los caricaturistas eran considerados como autores- artistas modernos o se auto-identificaban como artistas-intelectuales. El uso del humor gráfico era un recurso crítico y/o de exploración estética con el que intentaban construir un espacio o campo moderno del arte, deliberadamente autónomo de convenciones sociales. Esta actitud encontraba su fundamento en la propia autonomía de la obra de arte, en este caso, la caricatura. 
políticas o por las tendencias políticas: "la perspectiva estatal predominaba en las fuentes de información y la construcción de opiniones", puesto que el periodismo todavía no se había constituido como carrera universitaria y las "escuelas" de formación eran las mismas salas de redacción. Este autor manifiesta la influencia de los propietarios de los diarios en la UNP, lo que permitiría analizar si la profesión periodística logró autonomía.

Este artículo examina los documentos generados por la Unión Nacional de Periodistas, tanto de la época de su fundación como las publicaciones que se realizaron en lo posterior en las memorias de la organización, consideradas como fuentes primarias, cuyo contenido dialoga con estudios relevantes de autores que, desde el enfoque de la historia social, permiten reconocer las principales características y las tendencias de las primeras décadas del Ecuador del siglo $X X$. Esta aproximación al contexto de la época es posible gracias a las contribuciones realizadas por Guillermo Bustos, quien en diversos artículos permite comprender, por una parte, los fenómenos relacionados con los movimientos sociales y las demandas de derechos gremiales y sindicales desde la década de 1930; y, por otra parte, las características de una sociedad en transición hacia procesos modernizantes en donde confluían de manera conflictiva la diversidad de intereses, clases sociales, grupos étnicos, identidades e imaginarios sociales, especialmente en Quito, momento en el que se inscribe la conformación de la UNP.

Para la interrelación entre el contenido de los discursos del gremio de los periodistas y el contexto, se recurre también a los estudios realizados por la autora Kim Clark, quien analiza las propuestas y políticas inscritas en diferentes discursos de actores sociales de la época, en torno a la visión sobre las identidades del mestizaje y la mirada sobre el otro, el indígena, dentro de los proyectos para construir la nación. Algunas de las ideas e ideologías que circularon en la época permearon los discursos de los periodistas y las prácticas emprendidas en la búsqueda del afianzamiento y configuración del campo profesional.

Para comprender la noción de esfera pública se revisan los aportes de la autora María Elena Bedoya (2010) en un estudio sobre el origen de la prensa y la apertura del espacio público en la Audiencia de Quito. Si bien esta investigación hace referencia a finales del siglo XVIII, el ideal de la ilustración, que impulsó las primeras publicaciones, encuentra validez en los siglos siguientes, como un motor de la dinámica cultural de los periodistas, que con las diferencias pertinentes de las épocas, podría ser aplicado para el momento de estudio propuesto en este artículo. 
El concepto de campo de Bourdieu es utilizado como un eje articulador para captar las prácticas sociales organizadas por los periodistas con objetivos determinados, contribuye a identificar el espacio social agenciado por sus propios actores y el capital simbólico que funda- menta su agremiación e incidencia en la esfera pública. Si bien este artículo tiene una mirada sincrónica, en una coyuntura de 1940 a 1950, su contenido pretender despertar un interés en el debate y la reflexión con una perspectiva diacrónica, de larga duración hasta la actualidad.

\section{PERIODISMO DECIMONÓNICO Y LA MODERNIZACÓN DE LA PRENSA}

Con el surgimiento de las primeras publicaciones de prensa, en Europa y América Latina, se configuró la tendencia a difundir ideologías y el pensamiento político desde distintos locus de enunciación, principalmente desde el estado y por individuos o grupos que intentaban contrarrestar las políticas y discursos de poder. Siguiendo esta tradición, la prensa ecuatoriana desde fines del siglo XIX configuró, paulatinamente, espacios de interpelación política, significativos, en momentos trascendentes de la independencia y en la república del siglo XIX, protagonizados por periodistas que se convirtieron en grandes polemistas, quienes desde distintas vertientes ideológicas fundaron un estilo de prensa "panfletaria y dura, una trinchera" para combatir a los adversarios políticos hasta el punto de llegar a la intemperancia (Albán, 1996 ).

La prensa decimonónica expresaba la violencia, en un siglo atravesado por guerras civiles, crisis económica, autoritarismo, inestabilidad política e ideologías contrapuestas. Existieron centenares de publicaciones, efímeras, de un tipo de periodismo "exclusivamente doctrinario, acérrimo, que no daba ni pedía cuartel" (Albornoz, 1946), en doble vía entre los gobernantes e individuos críticos del poder. Luego de los temas debatidos sobre el bien público en la época de los primeros ilustrados de fines del siglo XVIII, ${ }^{4}$ que abrieron el camino para la construcción del espacio público (Bedoya, 2010), la prensa fomentó la

${ }^{4}$ Entendido en el sentido propuesto por J. Habermas como "un espacio conceptual en el que los particulares debaten asuntos públicos y se forma la opinión pública”. El estudio de María Elena Bedoya pone al descubierto el papel de la llustración, con el impulso de las letras en la Audiencia de Quito, Eugenio Espejo y Joseph Pérez Calama, a través de la lectura y las tertulias para la reflexión que estarían en el origen de la formación de la opinión pública. 
opinión alrededor de intensos debates sobre la censura y la defensa de la libertad de imprenta, defendida al calor de las ideologías: conservadora, liberal o francmasónica, plasmadas en diversos escritos publicados en periódicos, revistas y otros.

Estos escenarios de debate se configuraron, de manera principal, en las ciudades de Quito, Guayaquil, Cuenca y Ambato. ${ }^{5}$ Por lo general, los periódicos eran coyunturales por su misma naturaleza, una vez que habían cumplido su papel político (por ejemplo al final de un gobierno) tendían a desaparecer. Inclusive la prensa de gobierno carecía de organicidad debido a su propio origen de coyuntura. En esta medida, el periodismo del siglo XIX no logró consolidarse como un campo autónomo, libre de las contingencias partidistas y políticas ni, en rigor, era aún un campo profesional; en su lugar encontramos que la escritura de prensa era un oficio ejercido por quienes tenían la necesidad de expresar ideas de individuos, ideologías representativas de grupos o por afición. Tampoco se había definido todavía un perfil de periodista, puesto que quienes escribían en la prensa también eran autores literarios o cumplían una función política. Esta relación estrecha, entre el quehacer periodístico, literario y político, existió aún en las primeras décadas del siglo XX. La identidad del periodista y del campo profesional obedecen a ciertas condiciones de una época moderna.

El periodismo informativo y comercial empezó a desarrollarse en el Ecuador a fines del siglo XIX, en el segundo auge del cacao (1870-1920) que trajo dinamismo en la Costa, particularmente, a Guayaquil, como centro de una gran variedad de actividades comerciales de compra y venta de productos, gracias a su condición de puerto. La publicación cada vez más frecuente de oferta servicios y mercancías dio lugar al diarismo de prensa, por ejemplo, el Diario de Avisos, el Diario de Guayaquil y, luego, El Telégrafo que se transformó, de diario político y de combate, en informativo y de opinión (Destruge, 1924). A inicios del siglo XX este medio utilizó tecnología moderna y mantenía de manera exclusiva un servicio cablegráfico de noticias de la Agencia Hervas, que le permitió acceder a la información de los sucesos de la Primera Guerra Mundial (1914-1918).

Por otra parte, en este contexto de mayor dinámica comercial, los formatos de los periódicos también se

\footnotetext{
${ }^{5}$ El texto de Albán, E. (1988), Literatura y periodismo en el siglo XIX" revela los núcleos de la producción literaria y periodística del siglo XIX, en tres principales espacios: La Sierra Centro, compuesto por los periodistas y escritores literarios de Ambato; la Sierra Sur enfocada en el periodismo y literatura de la ciudad de Cuenca; y la Costa alrededor del núcleo de Guayaquil.
} 
modernizaban, gracias al uso de publicidad basada en la técnica del dibujo que combinaba las imágenes con el texto; luego se incorporó la fotografía, un invento moderno que cambió la estructura informativa de los periódicos. El diario El Comercio, fundado en Quito, en 1906, refleja el rol económico de la prensa en un momento de crecimiento del mercado local por la producción agrícola, la compra-venta de tierras y de propiedades, por la oferta de servicios, la moda, productos de higiene y salud entre otros. Expresa, además, la renovación tecnológica gracias a la adquisición de varias máquinas de tipografía, fotografía, fotograbado y encuadernación. Esta modernización de los medios emergió en los procesos de cambios urbanos de inicios del siglo XX, en escenarios de mayor crecimiento poblacional de Quito y Guayaquil (Bustos, 1992), ciudades en las que se fundaron los periódicos que lograron hacia 1950 mayor posicionamiento, tales como El Comercio, El Día, El Telégrafo y El Universo.

A comienzos del siglo XX se habían modificado algunas condiciones económicas y sociales que también influyeron en la modernización de la prensa, en un lento proceso que abriría el paso a la conformación del campo periodístico profesional, solo visible hacia mediados de siglo. Como en Europa, aunque con la asimetría de cada contexto, la prensa moderna se desarrolló de manera paralela a los medios de transporte (Assa y Burke, 2002). La llegada de la revolución del vapor al Ecuador, gracias a la inauguración del Ferrocarril del Sur en 1908, trajo consigo "el concepto de conexión y movimiento de personas, ideas y mercancías". (Clark, 2004). Se transportaban los periódicos de las localidades y se creó un circuito interno, dinámico, de distribución y consumo de la información entre la Costa y la Sierra Centro Norte, con públicos de lectores que podrían mirar más allá de lo local e imaginar una comunidad nacional.

El rol del estado fue clave en el fomento de una prensa nacional con inversión en tecnología para las comunicaciones, como el telégrafo, esencial en la cobertura informativa de fuentes de larga distancia. Dentro del programa de los gobiernos liberales se realizaron reformas y se expidieron decretos a favor de la expansión de la prensa; el ferrocarril constituyó también un trasporte del ideal de la libertad de prensa en virtud de medidas concretas. En 1909 el Congreso decretó que:

el papel periódico podría ser transportado por tren al menor precio, que los vendedores de periódicos podrían viajar gratis y que cada diario tenía el derecho al uso gratuito de las líneas del telégrafo construidas a 
lo largo del ferrocarril, hasta 200 palabras por día (Clark, 2004)

Por otra parte, la ampliación de la cobertura educativa, extendida a las mujeres con el laicismo y la escuela pública, impulsó su participación paulatina en revistas y, en menor medida, en la prensa desde inicios del siglo XX. Según Goetschel (2007), las mujeres tuvieron iniciativas de su propia agencia histórica, se forjaron las primeras escritoras literarias y periodistas. ${ }^{6}$ La escritura femenina abrió canales de expresión de voces de mujeres en la esfera pública, luego de un prolongado silencio en los periódicos desde la fundación de la república, dado un lugar común de las mujeres en la estructura social ligado a roles del ámbito familiar y la vida privada. No obstante estos nuevos espacios escriturarios, la participación de las mujeres en la prensa del siglo XX fue incipiente y, probablemente, se convirtió en una especie de derecho a conquistar, en medio de un campo profesional apropiado tradicionalmente por los hombres.7

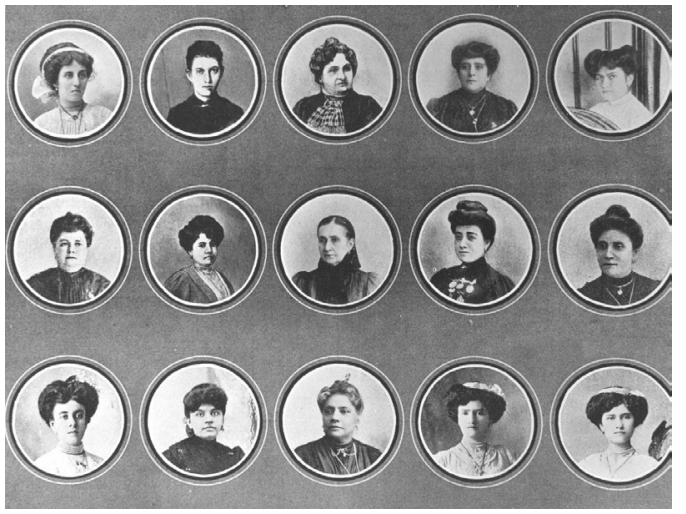

Fig. 1. Escritoras, poetisas e institutrices " 15 retratos de escritoras" Piedad Castillo, Angela Carbo, Dolores Sucre, Rita Lecumberri, Rosaura Emelia Galarza Directora de la Revista "La Ondina del Guayas". Guayaquil, 1910.

Fuente: Archivo del Ministerio de Cultura del Ecuador

\footnotetext{
${ }^{6}$ Entre las primeras revistas: La Mujer y Flora en las que se encuentran artículos que expresan las reflexiones de las primeras mujeres escritoras acerca de los roles femeninos, algunos vistos como retos, al iniciar el siglo XX. Para el estudio de este tema ver Goetschel, A. (2007). Educación de las mujeres, maestras y esferas públicas. Quito en la primera mitad del siglo XX. Quito: FLACSO-ABYA-YALA.

${ }^{7}$ La lenta inclusión de las mujeres en el campo del periodismo expresa que la modernización se produjo más en el plano tecnológico que en el ámbito de la consagración de los derechos de equidad de género, lo que a su vez pone de manifiesto que la revolución o innovación tecnológica de la prensa no produjo un cambio de mentalidades acerca de un rol tradicional femenino a favor del reconocimiento de un lugar de reconocimiento social de las mujeres en el espacio profesional.
} 
De manera concomitante, en las primeras décadas del siglo XX se encuentra un mayor desarrollo de los géneros periodísticos: la crónica, la caricatura, el reporterismo de prensa, que suponen la configuración de la opinión pública desde el punto de vista editorial del medio.

La caricatura, vista como un género periodístico, logró ampliar su incidencia en la Revolución Liberal (1895-1912), en las publicaciones de conservadores y liberales, con un alto contenido político. Sin embargo, entre la década de 1920 y 1930, la caricatura se planteó como un espacio de transgresión logrado por caricaturistas auto identificados dentro de

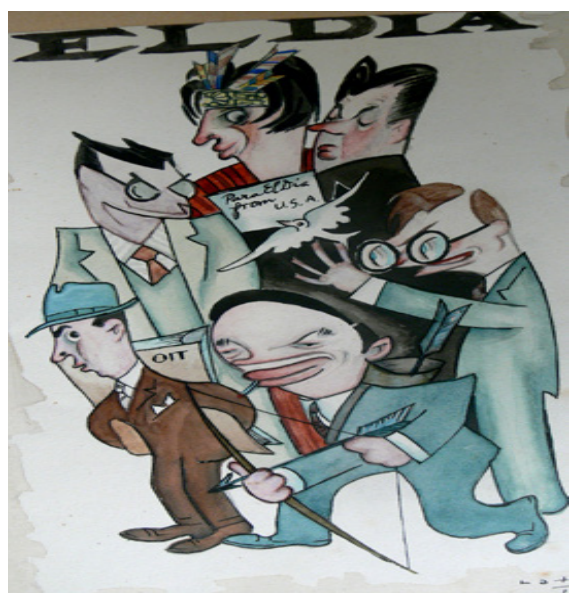

un campo de creación artística, relativamente autónomo de la política, por su sentido crítico a través del humor gráfico y la capacidad liberadora contemplada en la intención estética, distinto al ejercicio periodístico comprometido con la información de temas de coyuntura política. Más allá de las salas de redacción de la prensa, los caricaturistas se reunían en las salas de arte y construían sus propios medios de difusión e intercambio ${ }^{8}$, tales como las revistas ilustradas, al margen de las publicaciones de prensa "como un recurso alterno al texto escrito", aunque también publicaban en los diarios. (Bedoya, 2007).

Fig. 2. Periodistas de El Día.

Sr. Dr. Jaime Chávez Granja, Sr. Dn. Dr.Gabriel Garcés, Sr. Dn. Fernando Chávez, Sr. Dn. Reyes y Reyes Tupac Amaru, Sr. Dn. Julio Tronco Autor: Guillermo Latorre, 1945

Fuente: Biblioteca de la Casa de la Cultura Ecuatoriana

\footnotetext{
${ }^{8}$ Esta idea remite a la propuesta de J. Habermas (2009) para el contexto europeo que ubica el origen de la esfera pública en cafés y sitios de reunión, tertulias de los intelectuales. Ver también Hobsbawn, E. sobre la constitución del ámbito del periodismo, entre los años 1910 y 1920 en Europa. Allí se produjo una necesidad de modificar la primacía del arte por el periodismo en el espacio público, debido a que socialmente comienzan a posicionarse los medios en los públicos de lectores, se consume la prensa más que el arte.
} 
Fig. 3. Periodistas de El Comercio

Sr. Dr. Jaime Barrera, Augusto Arias, Gerardo Chiriboga, Raúl Andrade, Carlos Mantilla, Humberto Vacas y Alfredo Llerena 1951.

Autor: Guillermo Latorre

Fuente: Biblioteca de la Casa de la Cultura Ecuatoriana

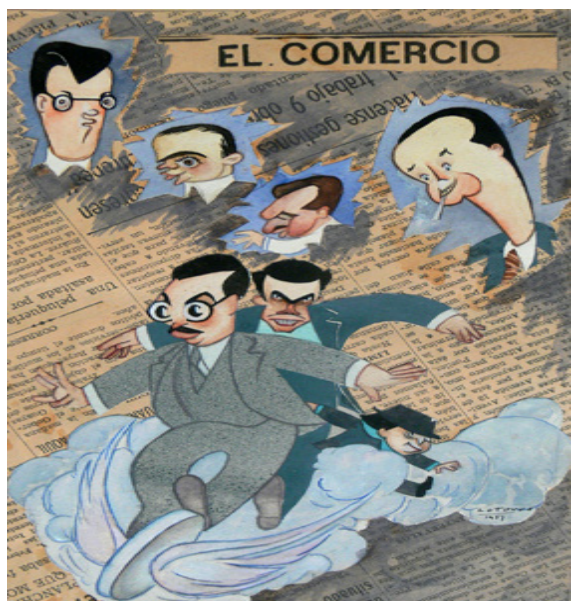

\section{EL ESPACIO SOCIAL, EL GREMIO Y EL CAPITAL SIMBÓLICO}

Si bien la génesis del periodismo en el Ecuador ha sido identificada a fines del siglo XVIII, a raíz de las primeras publicaciones de prensa a cargo de los ilustrados locales, las características del periodismo se distinguen como un campo profesional moderno, con mayor claridad desde 1940 cuando se fundó la Unión Nacional de Periodistas, organización que nació para el logro de diversos objetivos, en principio, gremiales y orientada a la profesionalización del periodismo.

Una mirada a las décadas de 1930 y 1940 en el Ecuador, revela que varias organizaciones sociales fueron conformadas por grupos de trabajadores de oficios, obreros y, en menor medida, por profesionales, alrededor de la demanda de derechos laborales para mejorar sus condiciones de vida, en medio de la crisis económica y política, post auge del cacao, de larga duración hasta mediados del siglo XX. El nacimiento de gremios y sindicatos constituía un fenómeno mundial de origen europeo, a manera de un modelo9, que se replicó con intensidad en el Ecuador, según Bustos (1990), en una crisis que "reordena el escenario so-

\footnotetext{
${ }^{9}$ Guillermo Bustos habla de una lógica de agremiación o modelo de organización sindical emergente en la época, categoría que explica la politización de los obreros que cobraron protagonismo en la esfera pública, en Quito entre 1930 y 1950
} 
cial y en la que los diferentes grupos sociales responden de forma diferenciada y activa a este reordenamiento". Estas organizaciones plantearon distintas estrategias políticas: la movilización social en el espacio público (en las calles y plazas), la publicación de manifiestos, sea para la interpelación al estado o a los patronos, para negociar derechos laborales. Postulaba algunas reivindicaciones de clase, propias de los partidos de izquierda, presentes inclusive en las proclamas de los gremios y sindicatos de carácter conservador.

La UNP se fundó en 1940 y adoptó algunos rasgos gremiales, puesto que obedecía a la lógica de las organizaciones sociales de la época, tal como se observa en la declaración de principios expuestos en el Primer Manifiesto ${ }^{10}$.

Al constituir una organización clasista de hombres de prensa, nuestro medular propósito fue el agrupar a los miembros activos de aquella, al servicio de un alto ideal de cultura que respondiese ampliamente al concepto institucional de lo que debe ser la prensa.

La UNP intentaba articular los intereses de los dueños de los periódicos y de los periodistas de oficio, empleados de las salas de redacción de las ciudades de Quito, Guayaquil, Cuenca y otras localidades de la Sierra y de la Costa. Precisamente se fundó por la iniciativa de algunos directivos de la prensa privada, de aquellos periódicos creados en las dos primeras décadas del siglo $X X$, que habían sobrevivido en el transcurso del tiempo por el capital económico invertido para la renovación tecnológica y por su administración como empresas rentables. Conforme al puente que extendieron los empresarios de la prensa con sus empleados, parecería ser que la UNP adoptó el rasgo del modelo sindical mixto "del abrazo entre el patrono y los trabajadores,"1 1 tal como se deja entrever en la siguiente cita:

"[...] gente de mayor o menor cultura general, aficionados a la tinta de imprenta, que por aquellos avatares de la vida habíamos tenido la suerte de trabajar al servicio de la prensa en el país, en los grandes rotativos como "El Comercio" de Quito, "El Telégrafo" y"El Universo" de Guayaquil, verdaderas escuelas prácticas de periodismo, acunados al calor de esos magníficos artífices del diarismo, como César

\footnotetext{
${ }^{10}$ El Comercio, 18 de Enero de 1940

${ }^{11}$ Como se narra en la película Metrópolis de Fritz Lang (1927) la relación entre el patrono y los obreros de una fábrica, quienes al final llegan a fraternizar a través de Freder, el personaje que encarna la capacidad mediadora, la negociación.
} 
y Carlos Mantilla, Manuel Eduardo, José Santiago y Abel Romeo Castillo [...] Una decena de años de diario bregar en la prensa, unas veces en la corrección de pruebas, otras en la ampliación y traducción de cables y telegramas" o en la dirección de armada y otras largas temporadas de reporteros recorriendo oficinas públicas, policía, entidades estatales y particulares en busca de noticias del día para satisfacer la innata curiosidad del lector eran razones más que suficientes para que pudiéramos llamarnos periodistas". (UNP, 1949)

Se trataría, de acuerdo con Bourdieu (2013), de un espacio social "habitado", entre los empresarios de la prensa y los periodistas empíricos, forjados en las salas de redacción, que reconocían su capital simbólico en el oficio de la escritura.
Esta toma de conciencia de la identidad de grupo y de intereses compartidos, impulsó la necesidad de profesionalizarse, conforme a los tiempos modernos, siguiendo el modelo emergente en otras regiones del mundo y que podía ser adoptado en el Ecuador: " Por qué nosotros jóvenes dedicados por entero al servicio de la prensa nacional, no podemos titularnos periodistas y no de cualquier manera sino con el aditamento de profesionales? (Manifiesto, 1940).

Se perfilaba un tipo de identidad basada en un saber-quehacer específico, que diferenciaba su lugar en el espacio social respecto de otras profesiones. ${ }^{12} \mathrm{El}$ campo periodístico, en su origen, estaba compuesto por una mayoría masculina, como se observa en todas las fotografías de la época, capturadas en diversas ciudades. ${ }^{13}$

\footnotetext{
${ }^{12}$ Se alude aquí al "principio de diferenciación" de los agentes situados en posiciones diferentes en el espacio social que: "no es más que la estructura de distribución de las formas de poder o de las especies de capital en el universo social considerado" (Bourdieu, 1997).

${ }^{13}$ Carlos A. Rolando identificó las mujeres escritoras, periodistas, ecuatorianas de las primeras décadas del siglo XX en: Cronología del Periodismo Ecuatoriano, Pseudónimos de la Prensa Nacional, Guayaquil, 1934. En este estudio se refleja la participación restringida de las mujeres en el periodismo. Esta tendencia se mantuvo al menos hasta la década de 1970. La UNP (1973), en La acción de la mujer en la actividad periodística, reconocía que "lamentablemente -la mujer- no ha incursionado en la medida que sería de desear" en el campo del periodismo; y auguraba una mayor participación femenina por medio del acceso a la carrera de periodismo, cuya demanda había crecido en aquellos años en las universidades.
} 


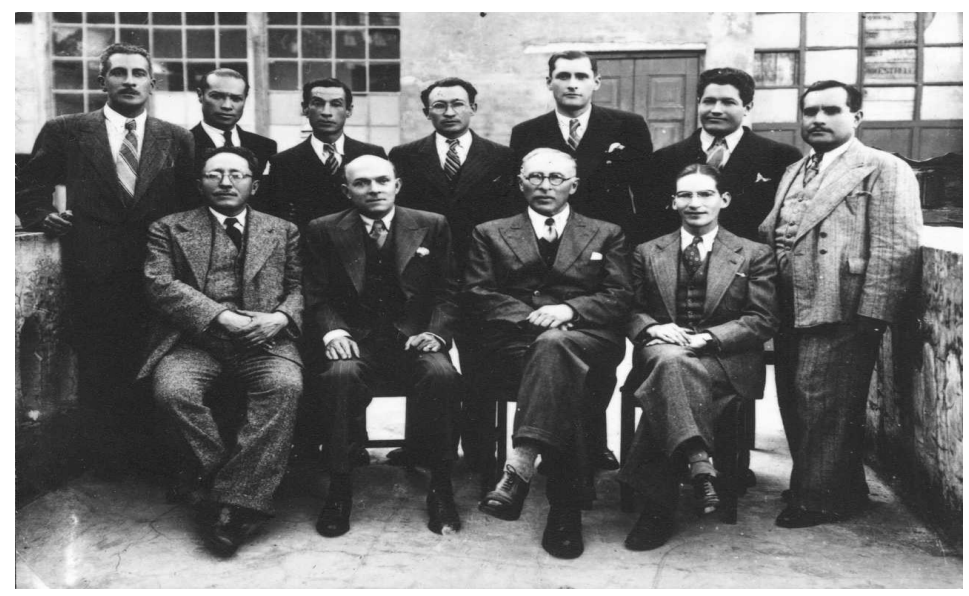

Fig. 4. Gremio de periodistas. Quito, 1940

Fuente: Archivo del Ministerio de Cultura del Ecuador

En cuanto a los intereses de gremio y de clase social, la UNP vigilaba los derechos laborales, defendía la escala de remuneraciones e intentaba, con ello, la estabilidad en los medios de prensa, puesto que gracias a la agremiación tendrían más posibilidades de existir y subsistir duraderamente (Bourdieu, 1997). Hacia los años 50 defendía la Ley del salario mínimo para todos los periodistas del Ecuador.

Para Bourdieu (1997), un campo -artístico o profesional- se logra por una labor simbólica de constitución y consagración necesaria para crear un grupo unido, mediante "la imposición de nombres, de siglas, de signos de adhesión, manifestaciones públicas y otras prácticas", puesto que así tendrían "tantas más posibilidades de alcanzar el éxito cuanto que los agentes sociales sobre los que se ejerce están más propensos a reconocerse mutuamente y a reconocerse en un mismo proyecto". Para afianzar el campo en el plano de las relaciones simbólicas, la UNP realizaba reuniones en espacios no formales de comunicación, externos al ámbito cotidiano del trabajo, para el entretenimiento, tales como fiestas y paseos. 


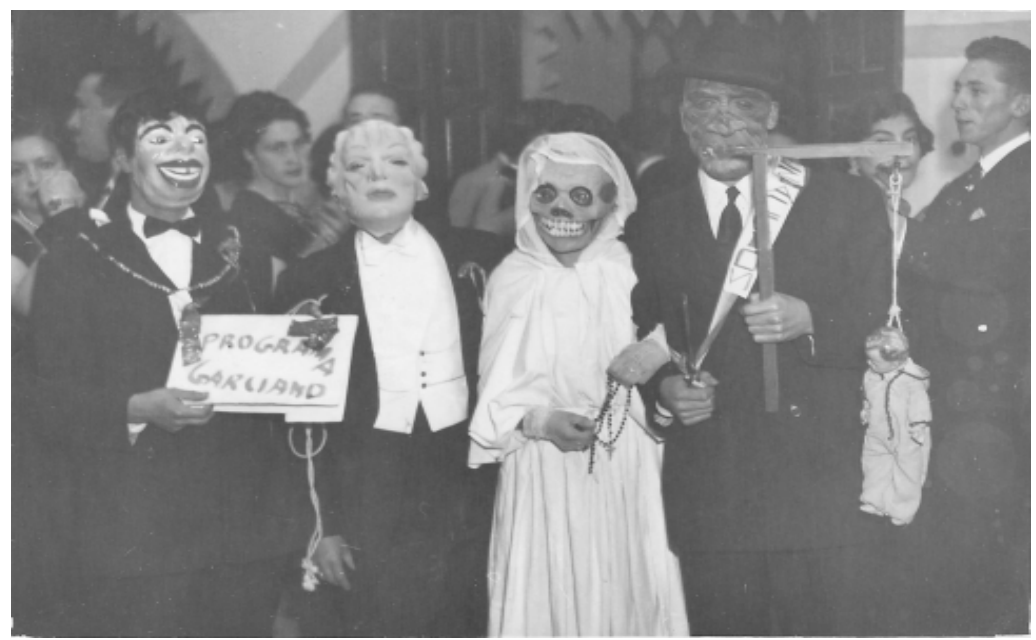

Fig.5. Baile de máscaras, Unión Nacional de Periodistas, Quito, 1952

Fuente: Archivo del Ministerio de Cultura del Ecuador

Uno de los objetivos más significativos de la UNP constituyó la búsqueda de una mayor incidencia en la esfera pública. Para ello planificaron a lo largo de la década de 1940 un conjunto de actividades y estrategias en las que ponían en juego su capital simbólico, a través de la publicación de artículos y de ensayos sobre temas que consideraban relevantes para la opinión pública. Abordaban problemas de coyuntura e impulsaron prácticas culturales en distintos escenarios del espacio público. Se trataba de una función intelectual, teórica y práctica, en palabras de Bourdieu (1997), que movilizaba al grupo alrededor de una labor colectiva y, de manera implícita, por y para la defensa de sus intereses profesionales.

\section{LA AGENDA PARA LA ESFERA PÚBLICA}

¿Cuál era el lugar de la UNP en la estructura social? ¿Alrededor de que tipos de capital organizó sus actividades? ¿Cuál era su rol social?
Los periodistas agremiados en la UNP iniciaron, a raíz de su creación, un proyecto conjunto de prácticas y manifestaciones públicas tendientes a 
consolidar el campo profesional en la esfera pública, en la que pondrían en juego su capital simbólico identificado: la escritura y el manejo de la información. Consideraban al periodismo como una profesión "consustancial con la democracia"14 (Albornoz, 1945), en tanto expresión del pensamiento y orientadora de la opinión para el progreso nacional. Redefinieron, entonces, un rol social fundado en la antigua tradición ilustrada, traída de la época colonial e inspirada en Eugenio Espejo, para "educar a las multitudes", a la mayoría de la población ecuatoriana (Albornoz, 1945), en una suerte de proyecto civilizatorio de la nación. Por medio de este rol intelectual de un saber y un saber-hacer, basado en el manejo de la escritura, bordearían también su posicionamiento en un campo de poder.

Para Bourdieu (2013), la movilización de los agentes dentro de la estructura del espacio social se impulsa a partir de la definición de un universo de problemas, a manera de coordenadas, que orientan la reflexión sobre los temas de interés en nombre del "bien público". Este nuevo rol intelectual del periodis- ta, según la UNP, consistiría en definir las prioridades del desarrollo nacional y conformar una agenda para la opinión pública, a manera de una "agenda setting", a ser tratada en la prensa, en ensayos de periodistas, publicados en textos y, aún más allá, como motivo de programas de acción en la sociedad.

Los temas de la agenda de los periodistas eran variados, desde lo que parecería ser superficial hacia lo más profundo: la necesidad de publicidad-propaganda para informar y evitar la distorsión, como herramienta para difundir la cultura nacional y "bellezas naturales" del Ecuador e impulsar por los medios el incipiente turismo (Darquea, 1946)..$^{15}$ Un problema expuesto por un escaso número de periodistas era la necesidad del apoyo del estado para garantizar la existencia de la prensa y la radiodifusión "sin encasillarse y sin confundir los intereses nacionales con los privativos del gobierno" (UNP, 1946). En resumen, la agenda definida por los periodistas planteaba una mirada diagnóstica de la realidad ecuatoriana, sobre problemas de carácter social, económico, cultural y político de vieja data, que causaban "retraso" de

${ }^{14}$ Las comillas son nuestras.

${ }^{15}$ Gustavo Darquea, redactor de El Comercio sostenía que "La publicidad es índice en la que se mide la cultura y el progreso del pueblo". Mientras que el gerente de Radio Quito, Gonzalo Bueno, de manera excepcional para aquella época reconocía la necesidad de profesionalizar la producción radial e "impulsar el progreso con música de otras culturas" para dejar de escuchar la "música triste". Para la revisión y análisis de los discursos de los periodistas de mediados de siglo XX, véase: Unión Nacional de periodistas (1946), Realidad y posibilidad del Ecuador. Quito. Biblioteca Aurelio Espinosa Pólit. 
la población y debían ser resueltos por el Estado y la sociedad en su conjunto.

En medio de la carencia de políticas educativas y culturales para la población, sobre todo del sector rural, la UNP atribuyó para sí, al gremio de periodistas, un rol protagónico en actividades de competencia del estado laico,16 con lo cual el campo profesional no cobraría autonomía de lo político.

Uno de los principales problemas sociales y culturales del Ecuador, en la agenda de la UNP, constituía el analfabetismo de "la masa" a la cual habría que redimirla "por todos los medios, y entre ellos los periodísticos" (Albornoz, 1946). En este problema se ancló la función educativa del periodista moderno. Cabe recordar que el analfabetismo constituía un tema abordado de manera recurrente en la época, dentro de los primeros proyectos de desarrollismo de mediados del siglo XX en América Latina. En este contexto, el programa estrella de la UNP de la década de 1940 fue la Campaña de Alfabetización, con contenido propio y orientado a las comunidades campesinas de la Sierra "región que recibió preferentemente el aporte de alfabetización" (UNP, 1949). La campaña tenía por objeto llevar el progreso o la ilustración al área rural, campesina e indígena, y a los obreros de la ciudad. El éxito sería relevante para los periodistas, puesto que se intentaba crear públicos de nuevos lectores, consumidores potenciales de la prensa, en aquellos lugares que eran alejados o recónditos en la geografía nacional.

Dicha campaña retomaba un concepto elitista sobre el lugar de los indígenas en la nación, puesto que, al ser una población analfabeta, eran considerados como "un peso muerto, factor de retraso y rémora" (Vallejo, 1946), discurso de poder replicado también en los ensayos de los periodistas. Este supuesto rol pasivo de los indígenas en la nación podría ser redimido mediante la educación para "civilizarlo". Esta idea había sido postulada en los estudios médico-higienistas y antropológicos de la época, reproducidos en los discursos de autoridades políticas y en los artículos de prensa, como por ejemplo en la propaganda que convocó a la población para el primer censo nacional de la población en 1950 (Clark: 1998). Esta intención civilizatoria fue impulsada por el naciente desarrollismo de estado a través de todos los gobiernos.

El indígena podría ser parte de la nación si se lo alfabetizaba, condición

\footnotetext{
${ }^{16}$ Para una aproximación a las diferencias delas políticas del estado ecuatoriano aplicadas al campo y la ciudad desde inicios del siglo XX, que explican ciertas brechas existentes en la configuración del estado liberal laico, proyectadas incluso hasta la actualidad, véase el artículo: Clark, K. La formación del estado ecuatoriano en el campo y la ciudad. En: Procesos, Revista Ecuatoriana de Historia
} 
sine qua non para que fuesen considerados ciudadanos. Se procuraba homogenizarlos en la cultura mestiza mediante la adquisición de las letras. En este sentido la UNP acogió en su campaña la visión hegemónica implícita en las políticas públicas, en las que el nexo entre educación y civilización parecía ser indisoluble. La educación convertiría a los indígenas en ciudadanos, portadores de la moral laica orientada, desde inicios de siglo, no solo a la adquisición de las letras sino también al cambio de costumbres, lejos de las prácticas culturales andinas, en pro de la higiene pública.

La Asamblea Nacional Constituyente de 1945, en el marco de las reformas de la denominada "La Gloriosa", aprobó el Plan Quinquenal para la alfabetización, propuesto por representantes del gremio de periodistas, gracias a lo cual la campaña de la UNP asumió un carácter oficial, al ser "patriótica, gratuita y nacional". Con el fin de ejecutarla se buscó la sinergia con varios actores sociales para un alcance territorial más amplio, apoyándose en la antigua estructura republicana de poder local de los poblados, vigente aun a mediados del siglo XX:

Los comités o centros de alfabetización que se extienden por todo el país, en cada parroquia o cantón o aun en los anejos de las haciendas, constituyen claros ejemplos de que es posible una cooperación entre los elementos locales, el teniente político, el cura parroquial y el maestro de escuela y que entre ellos bien pueden lograr obras de provecho común y patriótico y de ningún sentido político y unilateral (Vallejo, 1946).

La UNP implementó un Plan Fundamental de Educación dentro de la campaña antes mencionada: en la primera parte se enseñaba la escritura y la lectura; y en un segundo momento las lecturas de transición de cálculo, historia, geografía, higiene y virtudes cívicas; en fin "lo más indispensable para que un hombre pueda actuar por sí mismo y conducirse en la vida social como un factor positivo de progreso individual y colectivo" (Vallejo, 1946); es decir, convertirlo en ciudadano. Entonces, esta campaña intentó llevar la ciudadanía al campo y a las poblaciones marginales de la Sierra centro-norte. En el balance de la campaña realizada entre 1945 y 1946, se detectó que cincuenta mil beneficiarios más habían dejado de ser analfabetos, por ello la UNP les entregó "la carta de ciudadanía". Pero, ¿por qué este gremio asumía una función de competencia del estado? ¿Por qué la entrega de la ciudadanía se realizaba por este mecanismo y parecía ser considerada como un premio y no como un derecho? En principio cabe recordar que desde el inicio de la república los 
indígenas no fueron considerados como ciudadanos. Para mediados del siglo XX el reconocimiento de su ciudadanía estaba aún condicionada al hecho de saber leer y escribir para integrarse a la nación. Por otro lado, el rol de un estado débil, en cuanto a la administración del sistema de educación pública y a la cobertura en el territorio nacional, especialmente en las áreas rurales, confiaba la tarea de extender la educación a una organización de la sociedad civil, de carácter privado, como una suerte de deuda pendiente de la educación pública, laica y gratuita desde décadas atrás. En 1944 el presidente Velasco Ibarra firmó el convenio con la UNP con el fin de incorporar "a los habitantes del campo a una vida culta y civilizada" (Tuaza, 2010). De esta manera los periodistas, por su parte, lograrían reforzar su campo profesional y construir un espacio social para su empoderamiento.

En cuanto a los destinatarios directos de la campaña de alfabetización, en los campesinos, indígenas y obreros de las ciudades, sí hubo un impacto. Se podría valorar que, en el plazo inmediato, repercutió en los indicadores de la población censada en 1950, en cuanto a la población alfabeta y durante la década de 1950 incrementó de manera significativa el número de beneficiarios ${ }^{17}$

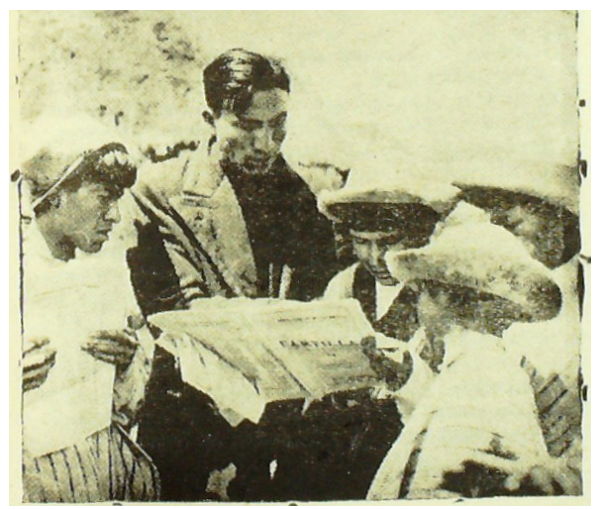

Fig.6. Campaña de Alfabetización de la UNP en Tungurahua, 1945

Fuente: UNP (1946). Realidad y posibilidad del Ecuador. Quito

\footnotetext{
${ }^{17}$ En 1958, la UNP había fundado 3484 centros escolares, alfabetizado a 150 289, nuevos ciudadanos, entre los cuales 90.000. Para el estudio del rol de la UNP en las comunidades indígenas en sus primeros 20 años de labores de alfabetización y la importancia de las letras para la población beneficiaria, se sugiere revisar el texto de Tuaza, L. (2010). Concepciones del Estado y demandas de las organizaciones campesinas e indígenas (1940-1960), en: Burbano de Lara, F. Transiciones y rupturas. El Ecuador en la segunda mitad del siglo XX. Quito: FLACSO.
} 
Por otro lado, la UNP, desde su origen, se autodefinió como: "un modelo de organización cultural, ya que en la prensa confluyen todos los anhelos vitales de la formación cultural de los grupos similares" (Manifiesto, 1940). Desde esta perspectiva, atribuyó a los periodistas un rol primordial en la difusión de la cultura nacional. Esta función consagraría el campo del periodismo por medio de una mayor incidencia social en las ciudades, mediante estrategias simbólicas desplegadas en los espacios públicos, relacionadas con la identidad cultural y el sentido de pertenencia a la nación.

La UNP absorbió los discursos de la época en torno a la cultura nacional y a la identidad ecuatoriana, desde distintas vertientes, aunque, de manera particular, produjo eco de la cultura hegemónica tradicionalista, como parte de un proyecto civilizatorio propio de mediados del siglo XX. Promovió actividades artísticas para difundir matrices histórico-culturales, opuestas y en conflicto, en el espacio social: la aborigen y la hispánica. En cuanto a la matriz andina, promovió el Primer Festival de Danza de los pueblos aborígenes del Ecuador, con lo cual reforzaba una tradición alrededor del folclore; y, por otro lado, reprodujo el hispanismo, en tanto matriz cultural propuesta por intelectuales y políticos insignes de la elite social quiteña desde la década de los 30 (Bustos, 2007), con lo cual contribuía a consolidar una tradición inventada en el sentido planteado por Hobsbawm (1983), sostenida también por el Municipio de Quito y por el sistema educativo.

La identidad hispánica fue promocionada tanto en los discursos de la prensa como en los desfiles, en las representaciones simbólicas en los espacios públicos, en las plazas y en las calles de la ciudad. El desfile de "Las Carretas del Rocío" y "Las Corridas de Gala de la Prensa", creadas por la UNP en la Plaza Arenas, en Quito, convocaban la concurrencia de la población y la participación de diversos actores, rituales transmitidas por la radio durante varios años. ${ }^{18}$ Estas actividades se organizaban también para obtener ingresos y "mantenerse al margen de las

\footnotetext{
${ }^{18}$ Estos espectáculos representaban lo hispánico y recreaban una la tradición fundada en la década de 1930, que retomaba el pasado colonial. El hispanismo nació a fines del siglo XIX y planteaba la existencia de una comunidad imaginada, una "gran familia transatlántica" compuesta por todos los pueblos que en un momento de su historia pertenecieron a la Corona española. Según Bustos (2001) el hispanismo como ideología descansó en el entrelazamiento de cuatro elementos centrales: religión católica, idioma castellano, sociedad jerárquica o corporativa y menosprecio de contribuciones culturales que no sean hispanas". Las prácticas de representación del hispanismo, señaladas en el estudio del rol de la UNP, contrastaban con las diversas manifestaciones de identidades étnicas, indígenas y mestizas, que coexistían de manera conflictiva en el espacio urbano como fruto de procesos de migración interna de las primeras décadas del siglo (Bustos, 1992).
} 
subvenciones de los gobiernos otorgadas a entidades culturales en el afán de mantener su absoluta independencia" (UNP, 1973).

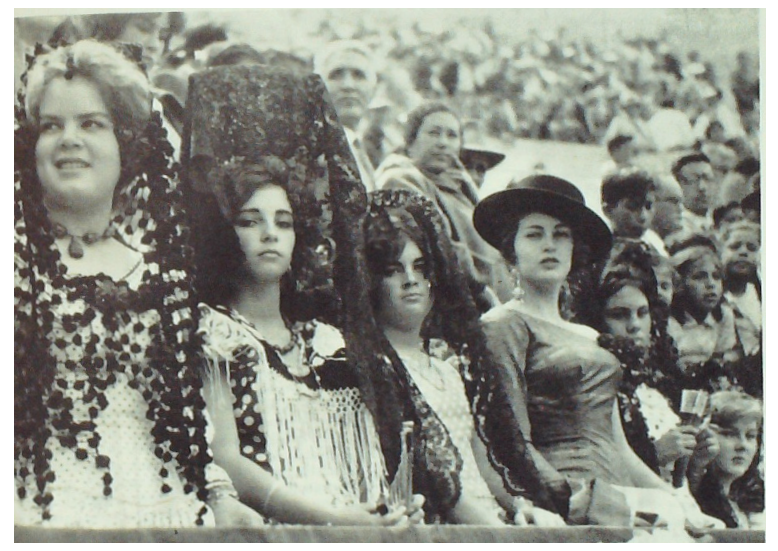

Fig. 7. Madrinas de la Corrida de la prensa organizada por la UNP, Quito, 1961 Fuente: Memoria de la UNP, 1973

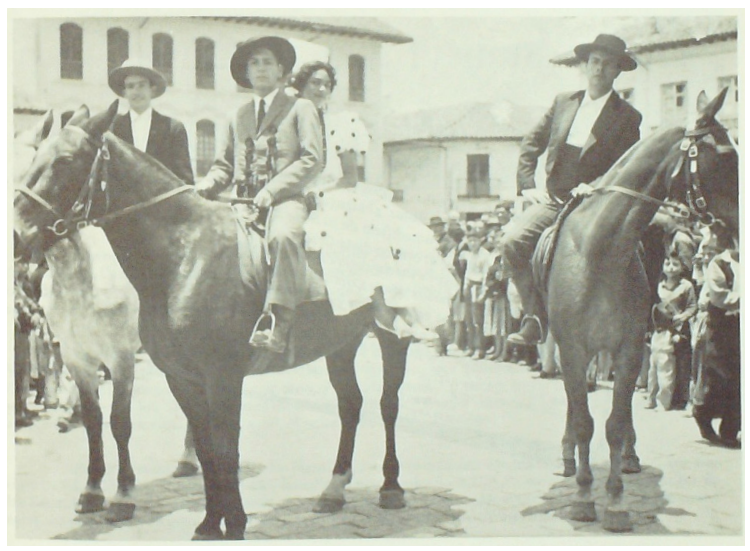

Fig. 8. Carretas de El Rocío en la Plaza de San Francisco, Quito, 1962

Con la participación de los estudiantes de colegios de la ciudad

Fuente: Memoria de la Unión Nacional de Periodistas 
En lo que corresponde a la modernización del periodismo como profesión, la UNP promovió el Primer Congreso Nacional de Periodistas, en 1947, con la asistencia de "lo más representativo de la prensa nacional, de todas las empresas e instituciones periodísticas, de las publicaciones no diarias y las radiodifusoras"; y organizó la Primera Exposición Nacional del Periodismo, a propósito del bicentenario del nacimiento de Eugenio Espejo (UNP, 1973). No obstante, conforme a los documentos de la época de estudio, se podría considerar que el gremio se inclinó más por el reconocimiento del periodista en el espacio social y el protagonismo en la esfera pública, a través del rol educativo y de difusión de la cultura nacional, que a la búsqueda de la cientificidad del campo, labor que habría sido promocionada con los primeras clases libres de periodismo y, posteriormente, cuando la Asamblea Nacional en 1945 autorizó la fundación de la primeras escuelas de periodismo en Quito y Guayaquil. ¿En esta propuesta pudo el gremio haber tenido algún tipo de agencia histórica?

La UNP intentó definir el campo el periodismo moderno basándose en una tradición ilustrada del dominio de las letras y se posicionó en espacios abandonados por un estado débil, carente de políticas públicas educativas; en tanto que apoyó la difusión de la cultura nacional

\section{CONCLUSIONES}

El giro hacia el periodismo moderno de mediados del siglo XX hacia un campo profesional, no implicó, de manera necesaria, un cambio radical o una ruptura en el ejercicio periodístico del pasado, por la presencia de vestigios de la tradición insertada en los discursos de la época, los cuales produjeron un eco en los ensayos periodísticos y en las publicaciones de prensa.

En la búsqueda de afianzar el periodismo como un campo profesional, la UNP configuró un campo de acción de mayor incidencia en la esfera pública, en donde los periodistas cobraron un rol protagónico, más allá de la escritura de prensa y su labor informativa. Trazaron la agenda de interés público a partir de un diagnóstico de la realidad ecuatoriana, con el supuesto de un nuevo rol intelectual dedicado a identificar los problemas sociales, a modo de una agenda setting, para orientar la opinión pública. Extendieron, entonces, estrategias de intervención social mediante programas y actividades edu- 
cativas y culturales, de esta manera los periodistas desbordaron los escenarios comunes de sus prácticas (las salas de redacción, el reporterismo en las oficinas y calles de las ciudades), y empezaron a habitar nuevos territorios, en el campo, en el mundo andino, a los que llegaron con un proyecto civilizatorio basado en las letras; y, en las ciudades, con la difusión de la cultura nacional hegemónica, cuyos efectos no han sido explorados hasta la actualidad.

Los periodistas usaron la escritura, su capital simbólico, como una herramienta de poder para incidir en la población rural y urbana. El estado, a su vez, delegó a los periodistas funciones públicas, por lo que, en el momento de este estudio, la prensa y el estado interactuaron, en una relación de doble vía de intereses mutuos, en nombre del bien público, pero interdependiente.

Dada la prioridad de la UNP de interactuar de manera directa con la población, se pudo constatar que el anhelo de profesionalización del gremio, hasta mediados del siglo XX, no se centró en la definición del objeto del periodismo moderno, con criterios de cientificidad, ni en una reflexión crítica acerca de los posibles efectos de su rol, en medio de una sociedad atravesada por conflictos de identidades culturales y por la confrontación de clases sociales, realidad a la que hacen referencia los estudios ubicados entre 1930 y 1950.

En la época analizada, próxima al origen del estado desarrollista, la asunción de las funciones, educativa y cultural, por parte de los periodistas, restringió la autonomía del campo respecto de la política, al tejer puentes con el estado y reproducir los imaginarios tradicionales de la sociedad. Esto deja al descubierto que el ideal de la libertad de expresión, anhelo vigente durante el siglo $X X$, se había condicionado a la agenda de la prensa y su relación coyuntural con otros actores sociales, sea este el estado -que como se ha visto se apoyó en la prensa-, dejando como deuda pendiente para el futuro la autonomía del campo. 


\section{BIBLIOGRAFÍA}

Albán, E. (1996). Literatura y Periodismo en el Ecuador, en: Ayala, E. (Ed.).Nueva Historia del Ecuador (vol. 8, pp. ). Quito: Corporación Editora Nacional.

Assa, B. y P. Burke. (2002) De Gutenberg a internet. Una historia social de los medios de comunicación. España: Taurus http:// www.proglocode.unam.mx/ sites/proglocode.unam.mx/ files/48651424-Burke-Peter-De-Gutemberg-a-Internet\%20(1).pdf

Baptista, P. (2009). Medios de comunicación. En: Fernández C. y L. Galguera. Teorías de la Comunicación (pp. ). México: Mc Graw Hill.

Bedoya, M. (2007). Los espacios perturbadores del humor. Revistas, Artey caricatura, 1918-1930. Quito: Banco Central del Ecuador.

Bedoya, M. (2010). Prensa y espacio público en Quito 1792-1840. Quito: FONSAL.

Bourdieu, P. (1997). Razones Prácticas. Sobre la teoría de la acción. Barcelona: Editorial ANAGRAMA.

Bourdieu, P. (2007). El sentido práctico. Buenos Aires: Siglo XXI

Bourdieu, P. (2011). Estrategias de reproducción social. Buenos Aires: Siglo $X X I$
Bourdieu, P. (2013). Efectos del lugar. En: Bourdieu, P. (Ed.) La miseria del mundo (pp. 120-132). Argentina: Fondo de Cultura Económica

Bustos, G. (1990). La politización del "problema obrero". Los trabajadores quiteños entre la identidad 'pueblo' y la identidad 'clase' (193134). Quito: www.uasb.edu.ec/ UserFiles/372/.../Politizacion\%20 del\%20problema\%20obrero.pdf

Bustos, G, (1992). Quito en la transición. Actores colectivos e identidades culturales urbanas (1920-1950). En: Aguilar, P. y otros. Enfoques y estudios históricos Quito a través de la historia (pp.). Quito: Dirección de Planificación. I. Municipio de Quito

Bustos, G. (2001). El hispanismo en el Ecuador. En: Porras, M. y P. Calvo (Coord.) Ecuador-España. Historia y perspectiva (pp. 150-159). Quito: Embajada de España en el Ecuador.

Bustos, G. (2007). Hispanización de la memoria pública en el cuarto centenario de fundación de Quito. En: Buschges, C. y otros (comp.). Etnicidad y poder en los países andinos (pp. 111-134). Quito: Corporación Editora Nacional

Carreño, J. (2007). Para entender los me- 
dios de comunicación. México: Nostra Ediciones.

Clark, K. (1999). La medida de la diferencia: las imágenes indigenistas de los indios serranos en el Ecuador (1920 a 1940). En: Cervone, E. y F. Rivera, Ecuador racista. Imágenes e identidades. Quito: FLACSO

Clark, K. (2004) La obra redentora. El ferrocarril y la nación en Ecuador 18951930. Quito: UASB-COPORACIÓN EDITORA NACIONAL.

Destruge, C, (1982). Historia de la prensa de Guayaquil (vol.4). Quito: Tipografía y Encuadernación Salesianas

Destruge, C, (1924). Historia de la prensa de Guayaquil (vol.2.) Quito: Tipografía y Encuadernación Salesianas

Goetschel, A. (2007). Educación de las mujeres, maestras y esferas públicas. Quito en la primera mitad del siglo XX. Quito: FLACSO-ABYA-YALA http://www.flacsoandes.edu.ec/ libros/digital/40087.pdf

Ibarra, H. (2015). Acción colectiva rural, Reforma Agraria y Política en el Ecuador, ca. 1920-1965. Tesis Doctoral. Madrid: Universidad Complutense-Fundación Instituo Universitario de Investigación José Ortega y Gasset.

Lochard, G. (2004). La comunicación mediática. Barcelona: Gedisa.
Habermas, J. (2009). Historia y critica de la opinión pública. La transformación estructural de la vida pública. Barcelona: Gili Gaya.

Hobsbawn, E. y T. Ranger (1983). La invención de la tradición. Barcelona: CRÍTICA

Larco, C. y L. Espinosa (2012). El pensamiento político de los movimientos sociales. Quito: Colección Pensamiento Político Ecuatoriano

Rolando, C. (1934). Pseudónimos de la prensa nacional. Guayaquil: Tip. y Lit. de la Sociedad Filantrópica del Guayas.

Tuasa, L. (2010). Concepciones del Estado y demandas de las organizaciones campesinas e indígenas (19401960). En: Burbano de Lara, F. (Coord.), Transiciones y rupturas. El Ecuador a mediados del siglo XX (pp. 465-513). Quito: FLACSO-Ministerio de Cultura.

Unión Nacional de Periodistas (1946). Realidad y posibilidad del Ecuador. Quito.

Vásquez, M. (1997). Historia de la Comunicación Social visión revisada y ampliada. Barcelona: CRÍTICA

Vallejo, G. (1946). El analfabetismo, mal americano. En: UNP, Realidad y posibilidad del Ecuador. Quito.

Warner, M. (2012). Público, Públicos y Contrapúblicos. México: Fondo de Cultura Económica. 
